This is a self-archived version of an original article. This version may differ from the original in pagination and typographic details.

Author(s): Calhim, Sara; Pruett-Jones, Stephen; Webster, Michael S.; Rowe, Melissah

Title: Asymmetries in reproductive anatomy : insights from promiscuous songbirds

Year: 2019

Version: Accepted version (Final draft)

Copyright: (c) 2019 The Linnean Society of London, Biological Journal of the Linnean Society

Rights: In Copyright

Rights url: http://rightsstatements.org/page//nC/1.0/?language=en

Please cite the original version:

Calhim, S., Pruett-Jones, S., Webster, M. S., \& Rowe, M. (2019). Asymmetries in reproductive anatomy : insights from promiscuous songbirds. Biological Journal of the Linnean Society, 128(3), 569-582. https://doi.org/10.1093/biolinnean/blz100 
8

\section{Asymmetries in reproductive anatomy: insights from promiscuous songbirds}

2 Sara Calhim ${ }^{1 *}$, Stephen Pruett-Jones ${ }^{2}$, Michael S. Webster ${ }^{3}$, and Melissah Rowe R $^{4,5}$

3

$4 \quad{ }^{1}$ Department of Biological and Environmental Science, P.O. Box 35, FI-10014 University of Jyväskylä, $5 \quad$ Finland

$6 \quad *$ Corresponding author. Email: s.calhim@gmail.com

$7 \quad{ }^{2}$ Department of Ecology and Evolution, University of Chicago, 1101 East $57^{\text {th }}$ St., Chicago, IL 60637, USA

$8{ }^{3}$ Cornell Lab of Ornithology, Cornell University, 159 Sapsucker Woods Road, Ithaca, NY 14850, USA

$9 \quad{ }^{4}$ Natural History Museum, University of Oslo, 0562 Oslo, Norway

$10{ }^{5}$ Centre for Ecological and Evolutionary Synthesis, Department of Biosciences, University of Oslo, 0316

11 Oslo, Norway

13 Short title: Avian reproductive tract asymmetry 


\section{Abstract}

15 Directional asymmetry in gonad size is commonly observed in vertebrates and is particularly pronounced 16 in birds, where the left testis is frequently larger than the right. The adaptive significance of directional 17 asymmetry in testis size is poorly understood, and whether it extends beyond the testes (i.e. side18 correspondent asymmetry along the reproductive tract) has rarely been considered. Using the Maluridae, a 19 songbird family exhibiting variation in levels of sperm competition and directional testis asymmetry, yet 20 similar in ecology and life-history, we investigated the relative roles of side-correspondence and sperm 21 competition on male reproductive tract asymmetry at both inter- and intraspecific levels. We found some 22 evidence for side-correspondent asymmetry. Additionally, sperm competition influenced directional 23 asymmetry at each end of the reproductive tract: species experiencing higher levels of sperm competition 24 had a relatively larger right testis and relatively more sperm in the right seminal glomerus. Within red25 backed fairy-wrens (Malurus melanocephalus), auxiliary males had relatively more sperm in the left 26 seminal glomerus in contrast to a right-bias asymmetry throughout the reproductive tract in breeding males. 27 Since sperm numbers are important for competitive fertilization success, our results suggest that sperm 28 competition shapes reproductive asymmetries beyond testis size, with likely functional consequences for 29 male reproductive success.

31 Keywords: sperm competition, testis size, Maluridae, reproductive evolution 


\section{Introduction}

34 Directional asymmetry in the animal kingdom is a widespread phenomenon that can affect whole body plans or the positioning, morphology or function of bilateral organs (reviewed in Palmer, 2004; 2009; Blum \& Ott, 2018). Asymmetries can be the result of natural selection processes, such as in the functionally asymmetric human brain or the asymmetric shape of the ciliate Paramecium (reviewed in Blum \& Ott,

38 2018). However, many cases of directional asymmetry are instead influenced by sexual selection, including 39 the species-specific chirality of snail shells (Davison et al., 2005), the asymmetric size of the fighting claws 40 of fiddler crabs (e.g. Rosenberg, 2002) and the non-random usage of the double intromittent organ of 41 phallostethid fishes (e.g. Parenti, 1986) and reptiles (Tokarz, 1988; e.g. Shine, 2000). Directional asymmetry in the size and/or shape (i.e. anterior-posterior elongation) of the testes is also widespread (e.g. Romer, 1971; Yu, 1998), and is particularly common and often pronounced in birds (Romer, 1971; Lake, 1981; Calhim \& Montgomerie, 2015). Avian gonads are internal and often show marked seasonal changes in size (Lofts \& Murton, 1973; Briskie \& Montgomerie, 2007). Although considerable intra- (reviewed in Calhim and Birkhead, 2009) and interspecific (e.g. Briskie \& Montgomerie, 2007; Calhim \& Montgomerie, 2015) variation in directional asymmetry in testis size and shape has been documented in birds, its evolutionary causes and consequences remain largely unexplored.

The majority of birds have a larger left testis (i.e. left-biased directional testis size asymmetry; Calhim \& Montgomerie, 2015). This pattern is suggested to be a by-product of strong selection for the degeneration of the right ovary and thus the occurrence of a single left ovary and left oviduct in female birds (Witschi, elongated left testis (i.e. left-bias testis shape asymmetry) has been documented in taxa with larger gizzards 56 (Calhim \& Montgomerie, 2015). Finally, the copulation bias hypothesis suggests that the function of the 57 larger left testis is to allow for greater sperm number insemination due to a match between left-bias 58 directional testis asymmetry and left-bias copulation direction (Petersen, Lombardo, \& Power, 2001; 59 Nyland, Lombardo, \& Thorpe, 2003; Delehanty \& O'Hearn, 2005). Testing this hypothesis requires 
60 quantitative data of copulation behavior across species that differ in the directional bias of testis asymmetry.

61 However, such data are rare since copulatory behavior of wild birds is often difficult to observe. Moreover, this hypothesis relies on the untested assumption of side-correspondent asymmetry throughout the reproductive tract, such as in sperm producing tissue, size of male sperm storage structures or numbers of sperm therein.

Surprisingly, the idea of whether or not asymmetry patterns across species extend beyond the testes to other components of the male reproductive tract is largely unexplored. Limited empirical evidence of asymmetry at the distal end of the reproductive tract comes from the Struthioniformes, Tinamiformes and Anseriformes: these groups have a phallus that tends to bend to the left when erect (King, 1989), corroborating the correlated evolution with female reproductive tract asymmetry (Witschi, 1935). In contrast, there is little information concerning asymmetry of lower reproductive structures in Passeriformes (but see Laskemoen et al., 2008 for a intraspecific study). In passerines, the distal end of each ductus deferens coils to form the seminal glomerus, structures that undergo seasonal changes in size in parallel with the testes, sometimes forming a pronounced sexually dimorphic feature - the cloacal protuberance (Wolfson, 1954; 1960; Lake, 1981). Thus, passerines offer an ideal group in which to investigate sidecorrespondent correlations between testis asymmetry and asymmetries in lower portions of the male reproductive tract.

Sperm competition is a key evolutionary force shaping variation in several primary sexual traits, including testis size and testis histology, sperm morphology, and sperm quality in wide variety of taxa (e.g. Simmons \& Fitzpatrick, 2012; Lüpold \& Pitnick, 2018), including birds (Briskie \& Montgomerie, 2007; Calhim \& Birkhead, 2007; Lüpold et al., 2009a,b; Rowe \& Pruett-Jones, 2011). In a comparative study covering 67 bird families, higher levels of sperm competition (i.e. relative testes mass) were associated with decreased asymmetry in testes (Calhim \& Montgomerie, 2015). This relationship, however, explained just $6 \%$ of the variation and was only statistically significant in taxa exhibiting left-biased directional asymmetry. Importantly, while broad comparative studies can be extremely informative, the large variation in selection pressures across such taxonomically diverse levels (i.e. different orders/families), as well as errors 
86 associated with diverse sources of data, can mask important biological patterns. Thus, while the sperm 87 competition hypothesis has received some support, there is much scope for additional studies.

In passerines, the degree and direction of directional testis asymmetry also varies within-species (reviewed 89 in Calhim \& Birkhead, 2009), and the former has been found to positively correlate with both age (e.g. 90 Birkhead et al., 1997; Merilä \& Sheldon, 1999; Graves, 2004) and the expression of male secondary sexual 91 characters (Møller, 1994). Møller (1994) suggested that the more symmetrical testes in lower quality males 92 reflected the compensatory growth of the typically smaller testis to compensate for the stunted growth and 93 thus assumed (anatomical or physiological) malfunction of the typically larger testis (Domm \& Juhn, 1927; 94 Calhim \& Birkhead, 2009). This pattern, however, was not observed in subsequent studies (reviewed in 95 Calhim \& Birkhead, 2009).

96 Due to potentially diverging evolutionary histories and selection pressures across avian families (Calhim $97 \&$ Montgomerie, 2015), a useful alternative approach is to examine primary reproductive trait asymmetry 98 variation within a limited taxonomic group exhibiting similar life-histories and ecology. The monophyletic 99 family Maluridae, which shows considerable variation in sperm competition levels and in directional testis 100 asymmetry, is emerging as a model system to study the evolution of avian mating systems and sperm 101 competition (Cockburn et al., 2013; Rowe \& Pruett-Jones, 2013). Malurids are small (c. 5-40 grams), 102 insectivorous passerines, and species tend to be similar to each other in general morphology and life-history 103 traits (e.g. long-lived, non-migratory, dome nests). Additionally, all species are known, or believed, to 104 exhibit cooperative breeding with sons and sometimes daughters remaining on their natal territory to assist 105 parents in raising subsequent offspring (Rowley \& Russell, 1997). Finally, malurids exhibit considerable 106 variation in potential sexual selection pressures and the intensity of sperm competition: despite being 107 socially monogamous, relative testes size varies ten-fold across species (c. $0.44-4.45 \%$ of male body 108 mass; Rowe \& Pruett-Jones, 2013) and the occurrence of extra-pair paternity (EPP) ranges from 6\% to 95\% 109 of broods (Mulder et al., 1994; Kingma et al., 2009; Rowe \& Pruett-Jones, 2013). Within the Maluridae, 110 the fairy-wrens (Malurus sp.) have received the most attention to date, likely due to their ease of study and 111 strong sexual selection pressures, suggested by their wide range in EPP rates and pronounced sexual 
112 dimorphism. This genus also shows pronounced plumage divergence among species (Johnson, Price, \& 113 Pruett-Jones, 2013), and in some cases variation in male plumage coloration within a species. The red-

114 backed fairy-wren is a clear example of a malurid with intraspecific variation in plumage colour (Karubian,

115 2002), and high levels of EPP (c. 63\% of broods contain extra-pair young; Webster, Varian, \& Karubian,

116 2008). Breeding male plumage types are associated with differences in male mating effort and behaviors:

$117 \mathrm{red} /$ black males, which are more attractive to females (Karubian, 2002), invest in EPP seeking behaviors,

118 whereas brown males invest in physical and acoustic mate guarding (defensive role in paternity; Karubian,

119 2002; Dowling \& Webster, 2017). Consequently, males are likely to face different sperm competition

120 levels: cuckolding red/black males in an offensive role for paternity, whereas brown males can behaviorally

121 prevent (e.g. mate guard) or reduce (e.g. frequent copulations) sperm competition in a defensive role.

122 Finally, helper males gain some limited paternity (Webster et al., 2008), always in offensive role. The male

123 types also differ in investment in gonads, as red/black males tend to have relatively larger testes compared

124 to brown males, and more so compared to helper males (Rowe et al., 2010). Therefore, this species is the

125 ideal complement to the interspecific analyses, allowing the corresponding assessment at the intraspecific

126 level.

127 Here, we investigate the degree of asymmetry across primary reproductive traits in male birds, using

128 malurids as a case study. Our main aim is to assess the roles of side-correspondent asymmetry and sperm

129 competition at both intra- and interspecific scales (Fig. 1A). This way, we can investigate the idea that

130 patterns of asymmetry may incorporate aspects of male reproductive anatomy beyond testis asymmetry,

131 and thus extend our knowledge of primary sexual trait asymmetry in studies of reproductive investment in 132 animals.

\section{Materials and Methods}

\section{Data collection}

135 Field methods 
136 Populations of ten species of Maluridae were studied at several sites across Australia between 2004-2006 137 and in 2011: superb fairy-wrens (M. cyaneus cyanochlamys) at Murray River National Park, South 138 Australia (140 $\left.32^{\prime} \mathrm{E}, 34^{\circ} 20^{\prime} \mathrm{S}\right)$; splendid (M. splendens melanotus), variegated (M. lamberti assimilis), and 139 white-winged (M. leucopterus leuconotus) fairy-wrens at Brookfield Conservation Park, South Australia $140 \quad\left(139^{\circ} 29^{\prime} \mathrm{E}, 34^{\circ} 20^{\prime} \mathrm{S}\right)$; blue-breasted fairy-wrens (M. pulcherrimus) at Lincoln National Park, South Australia $141\left(135^{\circ} 52^{\prime} \mathrm{E}, 34^{\circ} 52^{\prime} \mathrm{S}\right)$; red-backed fairy-wrens (M. melanocephalus) at Moomin Reservoir and Kalinvale 142 Farm, near Herberton, Queensland $\left(145^{\circ} 23^{\prime} \mathrm{E}, 1^{\circ} 23^{\prime} \mathrm{S}\right)$; red-winged fairy-wrens (M. elegans) near 143 Manjimup, Western Australia $\left(116^{\circ} 08^{\prime} \mathrm{E}, 34^{\circ} 15^{\prime} \mathrm{S}\right)$; lovely fairy-wrens (M. amabilis) near Julatten,

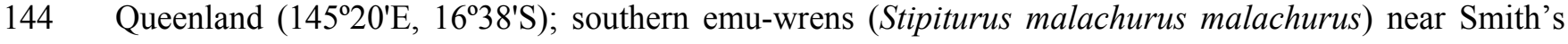
145 Lake, New South Wales $\left(152^{\circ} 28^{\prime} \mathrm{E}, 32^{\circ} 22^{\prime} \mathrm{S}\right)$; and striated grasswrens (Amytornis striatus striatus) at 146 Pooginook and Cooltong Conservation Parks, near Berri, South Australia (140 $\left.35^{\prime} \mathrm{E}, 34^{\circ} 16^{\prime} \mathrm{S}\right)$.

147 Adult birds were trapped using mist nets and song playback. Upon capture, birds were weighed $( \pm 0.1 \mathrm{~g})$ 148 using a Pesola spring balance and then euthanised in accordance with animal ethics approvals, and we 149 dissected out the testes and seminal glomera. Only males in peak breeding condition, indicated by 150 behavioral, morphological or physiological characteristics (e.g. breeding plumage, enlarged cloacal 151 protuberance, active spermatogenesis) were included in the study.

\section{Reproductive tract data}

153 We measured the length, width and fresh mass $( \pm 0.01 \mathrm{~g})$ of each testis and fresh mass of each seminal 154 glomerus separately. Testes were then fixed in 6-10\% neutral buffered formalin for 24 hours before being 155 stored in $70 \%$ ethanol. To determine the total number of sperm stored in each seminal glomerus, sperm 156 were flushed from each glomerus separately into a known volume of buffer (phosphate buffered saline in 157 2011, otherwise Lago Formulation Avian Semen Extender, Hygieia Biological Laboratories, USA), and 158 sperm numbers were quantified using a Makler counting chamber (Irvine Scientific, USA). We replicated 159 the counts using separate aliquots of the diluted sperm sample (Nakagawa \& Schielzeth, 2010), and 160 calculated an average sperm count based on the two replicates. All samples were mixed thoroughly before 161 counting. We also quantified the relative amount of spermatogenic tissue in each testis using standard 162 histological techniques and image analysis (Rowe \& Pruett-Jones, 2011). Briefly, for each of four non- 
163 sequential sections, we measured the proportion of seminiferous tubule tissue (relative to interstitial tissue)

164 using Image-J software and calculated the proportion of tissue per testis (i.e. left and right testis separately)

165 by averaging the values from the four sections.

166 Asymmetry measures

167 Asymmetry measures for all reproductive traits were calculated as a scale-free index (Palmer \& Strobeck,

168 2003) by taking the natural log from the ratio of the left-side measurement by the right-side measurement.

169 For example, testis size (i.e. mass) asymmetry (TA) $=$ natural $\log ($ left testis mass $[\mathrm{g}] /$ right testis mass $[\mathrm{g}]$ ).

170 We also calculated asymmetry index for seminal glomerus mass (SGA), seminal glomerus sperm numbers

171 (SGSNA), and proportion of sperm producing tissue in the testis (SPTA). Testis shape asymmetry

172 (TAshape) is also a scale-free index that reflects differences in the degree of elongation in the anterior-

173 posterior plane that was calculated as the difference between natural $\log$ (left testis length/right testis length)

174 and natural $\log$ (left testis width/right testis width). The absolute value of these scale-free indices reflects

175 the degree (i.e. the difference between the two sides) and their sign determines the bias (i.e. which side is

176 larger or longer), with positive and negative values corresponding to left and right bias, respectively.

177 Species-specific asymmetry indices were obtained by averaging asymmetry indices from all individuals

178 belonging to a species. The latter calculation led to some discrepancies between our data and the values

179 presented in Calhim and Montgomerie (2015). In that study, species-specific asymmetry indices were

180 calculated from species-level mean left and right side testis sizes, thus those values ignored intraspecific-

181 level variation. We present results using both approaches and show that they do not qualitatively affect our

182 results (Table 1 and Supplementary Table S1).

183 Gizzard size

184 Gizzard size data for five species: short-tailed grasswren (Amytornis merrotsyi merrotsyi), blue-breasted

185 fairy-wren, variegated fairy-wren, white-winged fairy-wren, and superb fairy-wren (subspecies leggei)

186 were obtained from the South Australian Museum. Gizzard volume was calculated from the available linear

187 dimensions of preserved specimens, assuming an ellipsoid shape: volume $=4 / 3 * \pi *(\text { length } / 2)^{*}(\text { width } / 2)^{2}$. In

188 our use of these data, we assumed the differences in gizzard size across subspecies in the superb fairy-wren

189 to be negligible. Similarly, in the absence of gizzard size data for the striated grasswren, the short-tailed 
190 grasswren was used. Though we fully acknowledge the potential error associated with these data, we 191 believe it is an acceptable compromise, since until recently these two taxa were classified as the same 192 subspecies and they share similar ecology and mating system (Christidis, 1999).

\section{Statistical analysis}

194 Interspecific patterns were analyzed taking into account the phylogenetic relationships among species, 195 which accounts for the expectation that closer relatives will be more similar to each other due to shared 196 evolutionary history (Felsenstein, 1985; Harvey \& Pagel, 1991). We used a generalized least-squares 197 approach within a phylogenetic framework ('pgls' function) using the packages 'caper' (Orme et al., 2013) 198 and 'ape' (Paradis, Claude, \& Strimmer, 2004) in R v. 3.5.2 (R Foundation for Statistical Computing, 2012). 199 We used the molecular phylogeny of Driskell et al. (2011), choosing this phylogeny over other available 200 phylogenies (e.g. Gardner et al., 2010; Lee, Joseph, \& Edwards, 2012) because of the availability of data 201 on branch lengths and because the main difference between available phylogenies concerns the positioning 202 of the purple-crowned fairy-wren, which is not included in our study. As well as intercept and slopes, this 203 analysis produces the phylogenetic scaling parameter $\lambda$ (an index between 0 and 1 ) and its $95 \%$ confidence 204 level (CL). This parameter $\lambda$ represents the degree of phylogenetic dependency in correlations among traits: 205 if $\lambda=1$, traits covary in direct proportion to their shared evolutionary history; while if $\lambda=0$, (i.e. trait 206 coevolution is independent of phylogeny; Freckleton, Harvey \& Pagel, 2002).

207 We were interested in testing and comparing non-exclusive yet alternative evolutionary paths to explain 208 interspecific patterns of asymmetry using four aspects of male reproductive tract morphology: testis mass, 209 proportion of sperm producing tissue, seminal glomerus mass, and number of sperm stored therein. We 210 investigated the associations between up and downstream traits (Fig. 1A paths 1-5, i.e. side211 correspondence), and the role of sperm competition (Fig. 1A paths 6-9). The strength of sperm competition 212 was estimated as relative testes mass, which we modelled by including both combined testes mass and body 213 mass as covariates in our models. This is a commonly used index in avian comparative studies (e.g. Calhim 214 et al., 2007; Lüpold et al., 2009a), including Maluridae (e.g. Rowe \& Pruett-Jones, 2013). In order to 215 directly compare path strengths (i.e. different models), we standardized all variables (i.e. subtracted the 
216 mean and divided by the standard deviation) prior to analyses. This way, model coefficients correspond to 217 standardized effect sizes, reflecting estimated unit change in the dependent variable per unit change in the 218 independent variable, where the unit is standard deviations.

219 The role of gizzard size on testis size and shape asymmetry was also tested using pgls analyses as described 220 above. However, since these relationships are not part of the path analyses in Fig. 1, standardized 221 coefficients were not required. Instead, we mean-centered the predictor variables so that the intercept 222 estimate reflects the asymmetry value predicted at the average gizzard size.

223 For the intraspecific patterns in reproductive asymmetry, we repeated the same analyses as for the 224 interspecies patterns (Fig. 1A). Phylogenetically controlled analyses were not needed, however, as these 225 data were from a single species - the red-backed fairy-wren. Instead, we used general linear models and 226 model plots to determine if the model assumptions were met. Importantly, this approach allowed us to 227 identify statistical outliers, which were then removed and the analyses repeated. We present the results with 228 the complete dataset, since (i) no qualitative differences were found between models with and without 229 outliers, (ii) close inspection of these 'outliers' showed no biological reason for their removal, and (iii) 230 samples sizes were already small. In these analyses, we used the reproductive morph of the male as the 231 index of sperm competition. Specifically, we categorized males into three morphs based on plumage 232 coloration and behavior: breeding males (red/black vs. brown) and non-breeding helper males. Plumage 233 color was determined by scoring the percentage of the male's body that was red/black versus brown 234 following Karubian (2002) and Lindsay et al. (2009). In general, and in the case of individuals utilized in 235 this study, these categories were discrete and unmistakable (Webster et al., 2008). The helper male morph 236 was set as the reference level in all statistical analyses, except those that included asymmetry in proportion 237 of sperm producing tissue in the testis (SPTA), as we had no data for individuals in this group.

\section{$238 \quad$ Ethical statement}

239 All work was undertaken with approval from the appropriate agencies, including the University of Chicago 240 Animal Care and Use Committee (\#71453), the Department of Environment and Heritage (South Australia) 241 Wildlife Ethics Committee (Project\# 13/2004; Scientific Permit Q24832; AW licence\# 142), the DirectorPage 10 of 25 
242 General of New South Wales Department of Primary Industries Animal Care and Ethics Committee 243 (06/3846; NSW NPWS scientific licence\# S12048), the Department of Environment and Conservation 244 (Western Australia; Regulation 17 licence\# SF008305; Regulation 4\# CE003378), James Cook University 245 Animal Ethics Review Committee (A1004 and A1691), the Environmental Protection Agency (EPA) of 246 Queensland, and the Department of Environment and Resource Management (Queensland; Scientific 247 Purposes Permit\# WISP09844011). Finally, export of samples from Australia was approved by the 248 Australian Government Department of Environment and Heritage (WT2005-10120, WT2006-10958 and 249 WT2012-10) and in accordance with Nagoya protocols.

\section{$250 \quad$ Results}

\section{Overview of reproductive tract asymmetry}

252 There was considerable inter- and intraspecific variation in asymmetry in all traits except the proportion of 253 sperm producing tissue (see Supplementary Tables S2, S3). The southern emu-wren showed the largest 254 intraspecific range in testis size asymmetry $(-0.56-0.47)$ and in proportion of sperm producing tissue ($2550.0118-0.0130$ ). This species also showed considerable variation in other asymmetry measures, making 256 it the most variable species in our dataset. The least variable species on average across all asymmetry 257 measures was the superb fairy-wren.

\section{$258 \quad$ Interspecific patterns}

259 We found that a larger right testis was associated with a larger investment in the right seminal glomerus 260 tissue (path 1/Table 1 and Fig. 1B; Fig. 2A). No other side-correspondent asymmetry paths were 261 statistically significant, although the trend was towards positive associations (paths $2-5 /$ Table 1 and Fig. 262 1B). We also found a significant negative association between relative testis size and testis size asymmetry 263 (path 6/Table 1 and Fig. 1B; Fig. 2B). Note that sperm competition explains two thirds of the variation in 264 testis size asymmetry within the Maluridae ( $c f .6 \%$ across 67 avian families; see Calhim \& Montgomerie 265 2015) In addition, there was a trend towards asymmetry in the number of sperm stored in the seminal 266 glomerus (path 8/Table 1 and Fig. 1B; Fig. 2C). Thus, as the level of sperm competition increased, 
267 asymmetry in testes size and seminal glomera sperm numbers shifted from left-biased to strongly right268 biased.

269 In contrast, we found no significant relationship between gizzard volume and either testis size or shape 270 asymmetry, once body mass was accounted for (Table 2). However, in our limited sample, there was a trend 271 for larger gizzards to be associated with a relatively larger right testis (Supplementary Fig. S1A) and more 272 elongated left testis (Supplementary Fig. S1B). However, this effect is likely due to a single species (i.e. 273 variegated fairy-wren) and as such these findings should be interpreted with caution.

\section{Intraspecific patterns}

275 We found no evidence of side-correspondent asymmetry in red-backed fairy-wrens (paths 1-5/Table 3). 276 However, we found that both types of breeding male showed, on average, symmetric sperm numbers in 277 their seminal glomera, while helpers exhibited considerable left bias (Table 3, Fig. 3, Supplementary Table 278 S3). Helpers also had significantly lower total number of stored sperm in the seminal glomera (helper mean $279 \pm$ SD sperm count $\left.\times 10^{6}: 26.18 \pm 15.98\right)$ relative to brown breeders $(108.62 \pm 78.11$; linear model estimate 280 mean \pm s.e. $=82.44 \pm 33.84, \mathrm{t}=2.44, \mathrm{p}=0.030$ ), although not significantly lower relative to red/black breeders 281 (69.72 \pm 29.83 ; estimate $=43.54 \pm 33.84, \mathrm{t}=1.29, \mathrm{p}=0.22)$. Although time of sampling had no effect on 282 breeding male asymmetry in numbers of sperm stored across species (Supplementary Table S4 and 283 Supplementary Fig. S2A), the helper vs. breeder morphs differences within the red-backed fairy-wren are 284 only present later in day (Supplementary Table S5 and Supplementary Fig. S2B).

\section{Discussion}

286 Directional asymmetry in testis size is widespread in birds, and varies from the strong left-side bias of the 287 Glaucous-winged gull (Larus glaucescens) to the extreme right-side bias in the African black coucal 288 (Centropus grilii), in which males lack the left testis entirely; though left bias in testis size is the common 289 pattern observed across bird species (c. 75\% of cases; Calhim \& Montgomerie, 2015). Here, we report 290 considerable interspecific variation in the direction and degree of testis size and shape asymmetry within a 
291 single avian family, the Maluridae. Moreover, we found, for the first time, that asymmetry in reproductive 292 tissues extends beyond testes size to include asymmetry in seminal glomera mass and the number of sperm 293 stored therein. In contrast, we found no evidence for asymmetry in the amount of sperm producing tissue 294 contained within the testis.

295 We observed considerable intraspecific variability among species in the degree of asymmetry in testis size 296 and shape, in seminal glomera size, and in the number of sperm stored therein. Broadly speaking, the 297 southern emu-wren and superb fairy-wren were, respectively, the most and the least variable species. 298 Concurrently, the southern emu-wren has the lowest rates of extra-pair paternity and relative testes mass, 299 while the superb fairy-wren has the highest rates of extra-pair paternity reported for the species in the 300 current study (Rowe \& Pruett-Jones, 2013). Though further work is clearly needed before firm conclusions 301 can be drawn, this pattern may suggest that the intense selection imposed via sperm competition in the 302 superb fairy-wren may reduce variation among males in a population such that all males are closer to a 303 species-specific 'optimum' investment in sperm production. Such a pattern would be similar to that 304 observed for sperm morphology, for which the level of sperm competition is associated with reduced 305 intermale variation in sperm size and shape in birds (Calhim, Immler, \& Birkhead, 2007; Kleven et al., 306 2008; Støstad et al., 2018) and other taxa (e.g. Fitzpatrick \& Baer, 2011).

307 Across species, we found that covariance between testis size asymmetry and relative testes mass (i.e. our 308 proxy of sperm competition) shifted from being left-biased in species with relatively low relative testes 309 mass to right-biased in species with high relative testes mass. In a larger comparative study of passerine 310 birds, Calhim and Montgomerie (2015) found that higher sperm competition was associated with more 311 symmetry in testis size, although this pattern was only statistically significant among taxa with a larger left 312 testis. Relative testes size, sperm production, and levels of extra-pair paternity in Malurids are among the 313 highest reported in passerine birds (Tuttle \& Pruett-Jones, 2004; Rowe \& Pruett-Jones, 2006; 2011; cf. 314 Griffith, Owens, \& Thuman, 2002; Rowe \& Pruett-Jones, 2013). Thus, our findings provide an interesting 315 contrast to previous work examining the role of sperm competition in shaping testes asymmetry across taxa. 316 Specifically, our study suggests that some malurid species may respond to the intense selective pressure of 
317 sperm competition by moving beyond testis size symmetry to right-biased asymmetry. Perhaps in small 318 passerines with relatively large gizzards (c. 4\% of body mass for Maluridae; passerine gizzard mass index: 319 mean \pm s.e. $=3.04 \pm 0.17, \mathrm{n}=22$; Calhim \& Montogomerie 2015) and strong selective pressure for larger 320 combined testes size, more testicular tissue can only be achieved by growing the less space-constrained 321 right testis. In fact, the degree of right-bias in testis size asymmetry values in malurids are among the most 322 extreme values reported for birds ( $c f$. Calhim \& Montgomerie, 2015). It may therefore be particularly 323 interesting to investigate if the same pattern occurs in other right-bias testis asymmetry clades with high 324 rates of extra-pair paternity, such as Hirundinidae or Fringillidae, and whether these clades also have a 325 relatively large gizzard.

326 Closer examination of the interspecific patterns provides some interesting contrasts. First, white-winged 327 fairy-wrens have both the largest relative testes size and the strongest right-bias in testes asymmetry. This 328 species exhibits a somewhat atypical 'clan' mating system (Rowley \& Russell, 1995), in which younger 329 males hold territories and are socially pair-bonded to a female, but exhibit female-like, brown plumage 330 (Pruett-Jones, unpublished data). Superimposed on these individual territories is the territory of a single 331 male in full nuptial plumage (i.e. blue/white plumage), and this male interacts with pairs occupying 332 individual territories within his 'clan' (Rowley \& Russell, 1995). Although this complicates our 333 understanding of extra-pair mating in this species, the occurrence of female multiple mating is undoubtedly 334 high in this species and thus strong selection imposed via sperm competition may explain the extreme 335 values we observed. Moreover, while the splendid and superb fairy-wren have right-bias in testes 336 asymmetry and high rates of extra-pair paternity (42-72\% extra-pair offspring; Rowe \& Pruett-Jones, 2013), 337 the red-winged fairy-wren shows left-bias asymmetry in testes mass despite comparably high rates of extra338 pair paternity (57\% extra-pair offspring; Brouwer et al. 2011; Rowe \& Pruett-Jones, 2013). Similarly, 339 relative testes mass is not particularly high in that species, which may suggest that selection on increasing 340 sperm numbers (i.e. through increases in tissue devoted to sperm production) is not especially strong in the 341 red-winged fairy-wren relative to that experienced by other high extra-pair paternity species; instead, 342 additional traits may be more closely linked to male fertilization success (e.g. sperm length), though such 
343 ideas remain to be tested. Nonetheless, overall our findings offer further support for the idea that sperm 344 competition can shape testes asymmetry in passerine birds.

345 Our results also shed light on the other hypotheses relating to interspecific variation in avian testis 346 asymmetry. First, we found no asymmetry in the proportion of sperm producing tissue in the testes at either 347 the inter- or intraspecific level. Second, in all individuals both the left and right testes appeared to be in a 348 state of full spermatogenesis (stage 6 sensu Scott \& Middleton, 1968). Together, this suggests that the two 349 testes are functionally equivalent, which contradicts the premise of the compensation hypothesis (Møller, 350 1994), namely that one testis is malfunctioning. The packaging hypothesis suggests that asymmetry in male 351 gonads reflects space constraints within the body cavity due to the positioning of organs such as the liver 352 (Witschi, 1935) and the gizzard (TR Birkhead, pers. comm.). We found that species with a relatively large 353 gizzard tended to have a more elongated and relatively smaller left testis. Although we acknowledge that 354 our results should be interpreted with extreme caution, these findings are consistent with the packaging 355 hypothesis and suggest that further studies investigating the role of space constraints in shaping testes 356 asymmetry would help elucidate the evolutionary causes of gonad asymmetry in birds. Our findings also 357 provide limited support for the key assumption behind the copulatory bias hypothesis (Delehanty \& 358 O'Hearn, 2005), where a strong side-correspondence in reproductive tract asymmetry is expected. We found 359 a significant interspecific positive association between testis and seminal glomerus size directional 360 asymmetries, but this relationship did not extend to the proportion of sperm producing tissue in the testis 361 or to sperm numbers stored in the seminal glomerus.

362 We found little evidence for a role of sperm competition in explaining intraspecific variation of 363 reproductive organ asymmetry. Specifically, asymmetry in reproductive organs did not differ between the 364 male reproductive phenotypes in the red-backed fairy-wren, with the exception of the number of sperm 365 stored in the seminal glomerus. In this instance, helpers exhibited strong left-bias in the number of stored 366 sperm, which stands in stark contrast to values observed in brown and red/black breeders. In general, 367 helpers appear to invest relatively little in sperm production relative to breeders in the red-backed fairy368 wren (Rowe et al., 2010) and, in this study, helpers had considerably fewer sperm in storage (1/3-1/4 of 
369 breeder values). Helpers also appear to obtain few mating opportunities relative to breeders, as helpers sire 370 a low proportion of the extra-pair young in a population (Webster et al., 2008). However, why this should 371 translate into left-bias asymmetry in numbers of stored sperm is unclear. One could speculate that the few 372 copulations helpers achieve are right-sided (in agreement with the copulation bias hypothesis for a species 373 with right biased testis size asymmetry), and their overall low sperm production did not replenish the right 374 seminal glomerus. The observation that helper vs. breeder differences are only clear in individuals sampled 375 later in the day further supports this hypothesis. However, given our small sample size for helper males, it 376 is plausible that this result constitutes a type I error, though the magnitude of the difference between helpers 377 and breeders might suggest otherwise.

378 The major contribution of our study is that we show that patterns of asymmetry in reproductive organs 379 extend beyond testes asymmetry to incorporate multiple aspects of male reproductive anatomy and 380 physiology. Most notably, we found that species exhibiting a larger right testis also possessed a larger 381 seminal glomerus on the right side, which is consistent with findings at the intraspecific level in the 382 bluethroat (Luscinia svecica; Laskemoen et al., 2008) and indicates the size of the seminal glomerus is a 383 function of testis size. Moreover, in addition to predicting a relatively larger right testis, high levels of 384 sperm competition tended to be positively associated with greater number of sperm stored in the right 385 seminal glomerus. In birds, sperm numbers are an important determinant of male fertilization success under 386 competitive mating conditions (Martin et al., 1974; Birkhead, 1998). Additional sperm phenotypic traits, 387 such as sperm size (Bennison et al., 2015) or sperm motile performance (Pizzari et al., 2008), also influence 388 male fertilization success in birds. However, recent theoretical and empirical work suggests that selection 389 imposed through post-copulatory processes (e.g. sperm competition and cryptic female choice) favors 390 increasing sperm numbers rather that sperm size in passerine birds, especially when the risk of sperm 391 competition is very high (Immler et al., 2011). Given that rates of extra-pair paternity are extremely high 392 in many of the malurids studied here, our results suggest that sperm competition can shape testes asymmetry 393 in the Maluridae with consequences for functional traits (i.e. sperm quantity) that influence the outcome of 394 sperm competition and, ultimately, male reproductive success. 
395 In conclusion, we show that directional asymmetry in male reproductive organs can incorporate multiple 396 aspects of the male reproductive tract. By utilizing a taxonomically restricted set of species, we aimed to 397 reduce potential sources of evolutionary variation in testes asymmetry to a primary variable of interest 398 the level of sperm competition. This approach allowed us to discover influential patterns in the asymmetry 399 of reproductive traits. Specifically, our findings suggest that sperm competition can shape reproductive 400 asymmetries in the Maluridae with likely functional consequences for male reproductive success, which in 401 turn suggests that extremely high sperm competition may push directional asymmetry of testes size towards 402 a right-bias in testis mass.

\section{Declaration of interest}

404 The authors declare no competing interests.

\section{Acknowledgments}

406 This work was funded by a Research Council of Norway grant (230434 to MR), and grants from the 407 National Science Foundation (0818962 to MSW; IOB-0516967 to SP-J). We would like to thank Lyanne 408 Brouwer, Martijn van de Pol, and Jan Lifjeld, as well as a number of field assistants, for their help and 409 support, Robert Montgomerie and two anonymous reviewers for helpful comments, and Philippa Horton 410 (South Australian Museum) for providing gizzard data.

\section{$411 \quad$ References}

412 Bennison C, Hemmings N, Slate J, Birkhead T. 2015. Long sperm fertilize more eggs in a bird.

413 Proceedings of the Royal Society B: Biological Sciences 282: 20141897.

414 Birkhead TR. 1998. Sperm competition in birds. Reviews of Reproduction 3: 123-129.

415 Birkhead TR, Buchanan KL, Devoogd TJ, Pellatt EJ, Szekely T, Catchpole CK. 1997. Song, sperm 416 quality and testes asymmetry in the sedge warbler. Animal Behaviour 53: 965-971.

417 Blum M, Ott T. 2018. Animal left-right asymmetry. Current Biology 28: R301-R304. 
418 Briskie JV, Montgomerie R. 2007. Testis size, sperm size and sperm competition. In: Jamieson B, ed. 419 Reproductive biology and phylogeny of birds. Part A. Phylogeny, morphology, hormones, fertilization. 420 Enfield, NH: Science Publishers, 513-551.

421 Brouwer, L, van de Pol, M, Atema, E, Cockburn, A. 2011. Strategic promiscuity helps avoid inbreeding at multiple levels in a cooperative breeder where both sexes are philopatric. Molecular Ecology 20: 47964807.

Calhim S, Birkhead TR. 2007. Testes size in birds: quality versus quantity - assumptions, errors, and estimates. Behavioral Ecology 18: 271-275.

Calhim S, Birkhead TR. 2009. Intraspecific variation in testis asymmetry in birds: evidence for naturally occurring compensation. Proceedings of the Royal Society B: Biological Sciences 276: 2279-2284.

Calhim S, Montgomerie R. 2015. Testis asymmetry in birds: the influences of sexual and natural selection. Journal of Avian Biology 45: 175-185.

430 Calhim S, Immler S, Birkhead TR. 2007. Postcopulatory sexual selection is associated with reduced 431 variation in sperm morphology. PLOS ONE 2: e413.

432 Christidis L. 1999. Evolution and biogeography of the Australian grasswrens, Amytornis (Aves :

433 Maluridae): biochemical perspectives. Australian Journal Of Zoology 47: 113.

434 Cockburn A, Brouwer L, Double MC, Margraf N, Van De Pol M. 2013. Evolutionary origins and 435 persistence of infidelity in Malurus: the least faithful birds. Emu 113: 208-217.

436 Davison A, Chiba S, Barton NH, Clarke B. 2005. Speciation and gene flow between snails of opposite 437 chirality (R Butlin, Ed.). PLoS Biology 3: e282-13.

438 Delehanty DJ, O'Hearn PP. 2005. Behavioral and morphological asymmetries in chukar Alectoris chukar 439 copulation. Journal of Avian Biology 36: 276-279.

440 Domm LV, Juhn M. 1927. Compensatory hypertrophy of the testes in brown leghorns. Biological Bulletin $441 \quad 52: 458-473$.

442 Dowling J, Webster MS. 2017. Working with what you've got: unattractive males show greater mate443 guarding effort in a duetting songbird. Biology Letters 13: 20160682.

444 Driskell AC, Norman JA, Pruett-Jones S, Mangall E, Sonsthagen S, Christidis L. 2011. A multigene 445 phylogeny examining evolutionary and ecological relationships in the Australo-Papuan wrens of the 446 subfamily Malurinae (Aves). Molecular Phylogenetics and Evolution 60: 480-485.

447 Felsenstein J. 1985. Phylogenies and the comparative method. American Naturalist 125: 1-15.

448 Fitzpatrick JL, Baer B. 2011. Polyandry reduces sperm length variation in social insects. Evolution 65: $449 \quad 3006-3012$.

450 Freckleton RP, Harvey PH, Pagel M. 2002. Phylogenetic analysis and comparative data: a test and review 451 of evidence. American Naturalist 160: 712-726.

452 Gardner JL, Trueman JWH, Ebert D, Joseph L, Magrath RD. 2010. Phylogeny and evolution of the 453 Meliphagoidea, the largest radiation of Australasian songbirds. Molecular Phylogenetics And Evolution 454 55: 1087-1102.

455 Graves GR. 2004. Testicular volume and asymmetry are age-dependent in black-throated blue warblers 456 (Dendroica caerulescens). Auk 121: 473-485. 
457 Griffith SC, Owens IPF, Thuman KA. 2002. Extra pair paternity in birds: a review of interspecific 458 variation and adaptive function. Molecular Ecology 11: 2195-2212.

459 Harvey PH, Pagel MD. 1991. The comparative method in evolutionary biology. Oxford University Press.

460 Immler S, Pitnick S, Parker GA, Durrant KL, Lüpold S, Calhim S, Birkhead TR. 2011. Resolving 461 variation in the reproductive tradeoff between sperm size and number. Proceedings of the National 462 Academy of Sciences 108: 5325-5330.

463 Johnson AE, Price JJ, Pruett-Jones S. 2013. Different modes of evolution in males and females generate 464 dichromatism in fairy-wrens (Maluridae). Ecology and evolution 3: 3030-3046.

465 Karubian J. 2002. Costs and benefits of variable breeding plumage in the red-backed fairy-wren. 466 Evolution 56: 1673-1682.

467 King AS. 1989. Phallus. In: King AS, McLelland J, eds. Form and Function in Birds. New York: 468 Academic Press, 459.

469 Kingma SA, Hall ML, Segelbacher G, Peters A. 2009. Radical loss of an extreme extra-pair mating $470 \quad$ system. BMC ecology 9: 15.

471 Kleven O, Laskemoen T, Fossøy F, Robertson RJ, Lifjeld JT. 2008. Intraspecific variation in sperm 472 length is negatively related to sperm competition in passerine birds. Evolution 62: 494-499.

473 Lake PE. 1981. Male genital organs. In: King AS, McLelland J, eds. Form and Function in Birds. New 474 York: Academic Press.

475 Laskemoen T, Fossoy F, Rudolfsen G, Lifjeld JT. 2008. Age-related variation in primary sexual 476 characters in a passerine with male age-related fertilization success, the bluethroat Luscinia svecica. 477 Journal of Avian Biology 39: 322-328.

478 Lee JY, Joseph L, Edwards SV. 2012. A species tree for the Australo-Papuan Fairy-wrens and allies 479 (Aves: Maluridae). Systematic Biology 61: 253-271.

480 Lindsay WR, Webster MS, Varian CW, Schwabl H. 2009. Plumage colour acquisition and behaviour are 481 associated with androgens in a phenotypically plastic tropical bird. Animal Behaviour 77: $1525-1532$.

482 Lofts B, Murton RK. 1973. Reproduction in birds. In: DS F, JR K, KC P, eds. Avian Biology. Academic 483 Press, 1-107.

484 Lüpold S, Pitnick S. 2018. Sperm form and function: what do we know about the role of sexual selection? 485 Reproduction: REP-17-0536.

486 Lüpold S, Linz GM, Rivers JW, Westneat DF, Birkhead TR. 2009a. Sperm competition selects beyond 487 relative testes size in birds. Evolution 63: 391-402.

488 Lüpold S, Calhim S, Immler S, Birkhead TR. 2009b. Sperm morphology and sperm velocity in passerine 489 birds. Proceedings of the Royal Society B: Biological Sciences 276: 1175-1181.

490 Martin PA, Reimers TJ, Lodge JR, Dziuk PJ. 1974. Effect of ratios and numbers of spermatozoa mixed 491 from 2 males on proportions of offspring. Journal of Reproduction And Fertility 39: 251-258.

492 Merilä J, Sheldon BC. 1999. Testis size variation in the greenfinch Carduelis chloris: relevance for some 493 recent models of sexual selection. Behavioral Ecology and Sociobiology 45: 115-123. 
494 Mulder R, Dunn P, Cockburn A, Lazenbycohen K, Howell M. 1994. Helpers liberate female fairy-wrens 495 from constrains on extra-pair mate choice. Proceedings of the Royal Society B: Biological Sciences 255: $496223-229$.

497 Møller A. 1994. Directional selection of directional asymmetry - Testes size and secondary characters in 498 birds. Proceedings of the Royal Society B: Biological Sciences 258: 147-151.

499 Nakagawa S, Schielzeth H. 2010. Repeatability for Gaussian and non-Gaussian data: a practical guide for 500 biologists. Biological Reviews of The Cambridge Philosophical Society 85: 935-956.

501 Nyland KB, Lombardo MP, Thorpe PA. 2003. Left-sided directional bias of cloacal contacts during house 502 sparrow copulations. The Wilson Bulletin 115: 470-473.

503 Orme D, Freckleton R, Thomas G, Fritz S, Petzoldt T, Isaac N, Pearse W. 2013. caper: Comparative 504 analyses of phylogenetics and evolution in $\mathrm{R}$.

505 Palmer AR. 2004. Symmetry breaking and the evolution of development. Science 306: 828-833.

506 Palmer AR. 2009. Animal asymmetry. Current Biology 19: R473-7.

507 Palmer RA, Strobeck C. 2003. Fluctuating asymmetry analyses revisited. In: Polak M, ed. Developmental 508 Instability. Oxford University Press, 279-319.

509 Paradis E, Claude J, Strimmer K. 2004. APE: Analyses of phylogenetics and evolution in R language. 510 Bioinformatics 20: 289-290.

511 Parenti LR. 1986. Bilateral asymmetry in phallostethid fishes (Atherinomorpha) with description of a new 512 species from Sarawak. Proceedings of the Californian Academy of Sciences 44: 225-236.

513 Petersen A, Lombardo M, Power H. 2001. Left-sided directional bias of cloacal contacts during tree 514 swallow copulations. Animal Behaviour 62: 739-741.

515 Pizzari T, Worley K, Burke T, Froman DP. 2008. Sperm competition dynamics: ejaculate fertilising 516 efficiency changes differentially with time. BMC Evolutionary Biology 8: 332.

517 Romer AS. 1971. The Vertebrate Body. Philadelphia: Saunders.

518 Rosenberg MS. 2002. Fiddler crab claw shape variation: a geometric morphometric analysis across the 519 genus Uca (Crustacea: Brachyura: Ocypodidae). Biological Journal of The Linnean Society 75: 147-162.

520 Rowe M, Pruett-Jones S. 2006. Reproductive biology and sperm competition in Australian fairy-wrens. 521 Avian and Poultry Biology Reviews 17: 21-37.

522 Rowe M, Pruett-Jones S. 2011. Sperm competition selects for sperm quantity and quality in the 523 Australian Maluridae. PLoS ONE 6: e15720.

524 Rowe M, Pruett-Jones S. 2013. Extra-pair paternity, sperm competition and their evolutionary 525 consequences in the Maluridae. Еmu 113: 218-231.

526 Rowe M, Swaddle JP, Pruett-Jones S, Webster MS. 2010. Plumage coloration, ejaculate quality and 527 reproductive phenotype in the red-backed fairy-wren. Animal Behaviour 79: 1239-1246.

528 Rowley I, Russell E. 1995. The breeding biology of the white-winged fairy-wren Malurus leucopterus529 leuconotus in a Western-Australian coastal heathland. Emu 95: 175-184. 
530 Rowley I, Russell EM. 1997. Fairy-wrens and grasswrens: Maluridae. In: Perrins C, Bock WJ, Kikkawa 531 J, eds. Bird Families of the World. Oxford University Press.

532 Scott DM, Middleton ALA. 1968. The annual testicular cycle of the brown-headed cowbird (Molothrus 533 ater). Canadian Journal of Zoology 46: 77-87.

534 Shine R. 2000. Are snakes right-handed? Asymmetry in hemipenis size and usage in gartersnakes 535 (Thamnophis sirtalis). Behavioral Ecology 11: 411-415.

536 Simmons LW, Fitzpatrick JL. 2012. Sperm wars and the evolution of male fertility. Reproduction 144: $537 \quad 519-534$.

538 Støstad HN, Johnsen A, Lifjeld JT, Rowe M. 2018. Sperm head morphology is associated with sperm 539 swimming speed: A comparative study of songbirds using electron microscopy. Evolution 49: 233-15.

540 Tokarz RR. 1988. Copulatory behaviour of the lizard Anolis sagrei: alternation of hemipenis use. Animal 541 Behaviour 36: 1518-1524.

542 Tuttle EM, Pruett-Jones S. 2004. Estimates of extreme sperm production: morphological and 543 experimental evidence from reproductively promiscuous fairy-wrens (Malurus). Animal Behaviour 68: $544541-550$.

545 Webster MS, Varian CW, Karubian J. 2008. Plumage color and reproduction in the red-backed fairy546 wren: Why be a dull breeder? Behavioral Ecology 19: 517-524.

547 Witschi E. 1935. Origin of asymmetry in the reproductive system of birds. American Journal of Anatomy 548 56: 119-141.

549 Wolfson A. 1954. Sperm storage at lower-than-body temperature outside the body cavity in some 550 passerine birds. Science 120: 68-71.

551 Wolfson A. 1960. The ejaculate and the nature of coition in some passerine birds. Ibis 102: 124-125.

552 Yu Z. 1998. Asymmetrical testicular weights in mammals, birds, reptiles and amphibia. International 553 Journal of Andrology 21: 53-55. 


\section{$556 \quad$ Figure Legends}

557 Figure 1. Schematic representation of the direct associations between side-correspondent development 558 (paths 1-5) or sperm competition (paths 6-9) and four primary sexual trait asymmetries along the male 559 reproductive tract: testis size asymmetry (TA), seminal glomerus size asymmetry (SGA), seminal glomerus 560 sperm number asymmetry (SGSNA), and proportion of sperm producing tissue asymmetry (SPTA). Sperm 561 competition was measured as relative testes size (combined testes mass, controlling for body mass). A: 562 General schematic representation; B: Patterns observed at the interspecific level. Arrow thickness denotes 563 standardized effect size $\mathrm{r}$ and the style the direction of the association (solid and dashed for positive and 564 negative, respectively). See Table 1 for complete statistical output.

565 Figure 2. Scatterplots (mean \pm s.e.) representing the three statistically significant and/or strongest 566 (standardized effect size $r>|0.66|$ ) interspecific associations (see Figure 1). (A) positive relationship 567 between testis size asymmetry and seminal glomerus size asymmetry (path 1); (B) negative association 568 between relative testes size and testis size asymmetry (path 6); and (C) negative association between 569 relative testes size and seminal glomerus sperm number asymmetry (path 8). Here, unlike in the analysis, 570 relative testes size is represented as the residuals of a phylogenetically controlled linear model of testes 571 mass on body mass, using standardized variables. Asymmetry values are scale-free indices (see main text 572 for details), with the absolute value reflecting the degree of difference and the sign denoting the directional 573 bias (positive and negative for left- or right-bias, respectively). Species codes: $1=$ lovely fairy-wren $(\mathrm{n}=4)$, 5742 =superb fairy-wren $(n=6), 3=$ red-winged fairy-wren $(n=6), 4=$ variegated fairy-wren $(n=5), 5=$ white575 winged fairy-wren $(n=6), 6=$ red-backed fairy-wren $(n=20), 7=$ blue-breasted fairy-wren $(n=5), 8=$ splendid 576 fairy-wren $(n=6), 9=$ southern emu-wren $(n=6), 10=$ striated grasswren $(n=6)$.

577 Figure 3. Differences in the asymmetry in the number of sperm in the seminal glomerus (mean \pm s.e.) 578 between the three male morphs in the red-backed fairy-wren. 


\section{$580 \quad$ Tables}

581 Table 1. Comparison of alternative paths to explain interspecific variation in asymmetry along the 582 reproductive tract in malurids.

\begin{tabular}{|c|c|c|c|c|c|c|c|c|c|}
\hline pathway* & model & coefficient $\S$ & estimate & s.e. & $\mathrm{t}$ & $\mathrm{p}$ & ML lambda & $\mathrm{R}^{2}$ & $\mathrm{n}$ \\
\hline \multicolumn{10}{|c|}{ Side-correspondent development } \\
\hline \multirow[t]{2}{*}{1} & SGA TA & intercept & -0.011 & 0.235 & -0.05 & 0.96 & 0.00 & 0.50 & 10 \\
\hline & & TAsize & 0.700 & 0.247 & 2.84 & 0.02 & & & \\
\hline \multirow[t]{2}{*}{2} & SGSNA $\sim$ SGA & intercept & 0.462 & 1.235 & 0.37 & 0.72 & 0.98 & 0.03 & 10 \\
\hline & & SGA & 0.137 & 0.299 & 0.46 & 0.66 & & & \\
\hline \multirow[t]{2}{*}{3} & SGSNA $\sim$ TA & intercept & 0.023 & 0.318 & 0.07 & 0.95 & 0.00 & 0.10 & 10 \\
\hline & & TAsize & 0.314 & 0.333 & 0.94 & 0.37 & & & \\
\hline \multirow[t]{2}{*}{4} & SGSNA SPTA & intercept & -0.061 & 0.345 & -0.18 & 0.87 & 0.00 & 0.30 & 8 \\
\hline & & tissueA & 0.590 & 0.373 & 1.58 & 0.16 & & & \\
\hline \multirow[t]{2}{*}{5} & $\mathrm{SPTA} \sim \mathrm{TA}$ & intercept & 0.091 & 0.386 & 0.24 & 0.82 & 0.00 & 0.07 & 8 \\
\hline & & TAsize & 0.306 & 0.447 & 0.69 & 0.52 & & & \\
\hline \multicolumn{10}{|c|}{ Sperm competition } \\
\hline \multirow[t]{3}{*}{6} & $\mathbf{T A} \sim \mathbf{B M}+\mathbf{C T M}$ & intercept & -0.014 & 0.214 & -0.07 & 0.95 & 0.00 & 0.65 & 10 \\
\hline & & $\mathrm{BM}$ & 0.382 & 0.241 & 1.59 & 0.16 & & & \\
\hline & & CTM & -0.862 & 0.241 & -3.58 & 0.01 & & & \\
\hline \multirow[t]{3}{*}{7} & $\mathrm{SGA} \sim \mathrm{BM}+\mathrm{CTM}$ & intercept & -0.019 & 0.32 & -0.06 & 0.96 & 0.00 & 0.19 & 10 \\
\hline & & $\mathrm{BM}$ & 0.158 & 0.36 & 0.44 & 0.67 & & & \\
\hline & & CTM & -0.465 & 0.36 & -1.29 & 0.24 & & & \\
\hline \multirow[t]{3}{*}{8} & SGSNA $\sim$ BM + CTM & intercept & 0.013 & 0.27 & 0.05 & 0.96 & 0.00 & 0.43 & 10 \\
\hline & & $\mathrm{BM}$ & 0.472 & 0.303 & 1.56 & 0.16 & & & \\
\hline & & CTM & -0.662 & 0.303 & -2.19 & 0.06 & & & \\
\hline \multirow[t]{3}{*}{9} & $\mathrm{SPTA} \sim \mathrm{BM}+\mathrm{CTM}$ & intercept & 0.066 & 0.328 & 0.20 & 0.85 & 0.00 & 0.38 & 8 \\
\hline & & $\mathrm{BM}$ & 0.337 & 0.329 & 1.02 & 0.35 & & & \\
\hline & & CTM & -0.598 & 0.351 & -1.70 & 0.15 & & & \\
\hline
\end{tabular}

* Pathway numbers correspond to those outlined in Figure 1.

$\S$ Coefficient estimates denote standardized effect size $r$, with statistically significant (or marginally non-significant) effects shown in bold text. TA=testis size asymmetry, SGA=seminal glomerus size asymmetry, SGSNA=seminal glomerus sperm number asymmetry,

$\mathrm{SPTA}=$ proportion of sperm producing tissue asymmetry, $\mathrm{BM}=$ body mass, $\mathrm{CTM}=$ combined testes mass, ML lambda=maximum likelihood estimated lambda. 
585 Table 2. Relationships between relative gizzard size and testis asymmetry in size and shape in malurids, 586 controlling for phylogeny.

\begin{tabular}{lllllllll} 
model & coefficient* & estimate & s.e. & $\mathrm{t}$ & $\mathrm{p}$ & ML lambda & $\mathrm{R}^{2}$ & $\mathrm{n}$ \\
\hline $\mathrm{TA} \sim \mathrm{BM}+\mathrm{GV}$ & intercept & -0.053 & 0.024 & -2.22 & 0.16 & 0.00 & 0.79 & 5 \\
& $\mathrm{BM}$ & 0.048 & 0.018 & 2.72 & 0.11 & & & \\
& $\mathrm{GV}$ & -0.920 & 0.368 & -2.50 & 0.13 & & & \\
TA shape $\sim \mathrm{BM}+\mathrm{GV}$ & intercept & 0.008 & 0.021 & 0.39 & 0.73 & 0.00 & 0.93 & 5 \\
& $\mathrm{BM}$ & -0.017 & 0.015 & -1.12 & 0.38 & & & \\
& $\mathrm{GV}$ & 0.826 & 0.321 & 2.57 & 0.12 & & & \\
\hline
\end{tabular}

* Coefficient estimates denote standardized effect size $\mathrm{r}$, with statistically significant (or marginally non-significant) effects shown in bold text. TA=testis size asymmetry, TA shape=testis shape asymmetry, BM=body mass, GV=gizzard volume, ML lambda=maximum likelihood estimated lambda. 
589 Table 3. Comparison of alternative paths to explain intraspecific variation in asymmetry along the 590 reproductive tract in red-backed fairy-wrens.

\begin{tabular}{|c|c|c|c|c|c|c|c|c|}
\hline pathway* & model & coefficient§ & estimate & s.e. & $\mathrm{t}$ & $\mathrm{p}$ & $\mathrm{R}^{2}$ & $\mathrm{n}$ \\
\hline \multicolumn{9}{|c|}{ Side-correspondent development } \\
\hline \multirow[t]{2}{*}{1} & $\mathrm{SGA} \sim \mathrm{TA}$ & intercept & -0.002 & 0.259 & -0.01 & 0.99 & 0.002 & 16 \\
\hline & & TA & 0.042 & 0.237 & 0.18 & 0.86 & & \\
\hline \multirow[t]{2}{*}{2} & $\mathrm{SGSNA} \sim \mathrm{SGA}$ & intercept & 0.000 & 0.231 & 0.00 & 1.00 & 0.20 & 16 \\
\hline & & SGA & 0.452 & 0.238 & 1.90 & 0.08 & & \\
\hline \multirow[t]{2}{*}{3} & SGSNA $\sim$ TA & intercept & 0.004 & 0.258 & 0.02 & 0.99 & 0.01 & 16 \\
\hline & & TA & -0.088 & 0.237 & -0.37 & 0.71 & & \\
\hline \multirow[t]{2}{*}{4} & SGSNA $\sim$ SPTA & intercept & -0.504 & 0.088 & -5.73 & 0.01 & 0.04 & 5 \\
\hline & & SPTA & 0.034 & 0.098 & 0.34 & 0.75 & & \\
\hline \multirow[t]{2}{*}{5} & $\mathrm{SPTA} \sim \mathrm{TA}$ & intercept & -0.047 & 0.500 & -0.09 & 0.93 & 0.09 & 5 \\
\hline & & TA & -0.251 & 0.464 & -0.54 & 0.63 & & \\
\hline \multicolumn{9}{|c|}{ Sperm competition } \\
\hline \multirow[t]{3}{*}{6} & $\mathrm{TA} \sim$ male morph & intercept (helper) & -0.015 & 0.063 & -0.24 & 0.81 & 0.07 & 4 \\
\hline & & vs brown breeder & -0.077 & 0.076 & -1.01 & 0.32 & & 9 \\
\hline & & vs red/black breeder & -0.015 & 0.074 & -0.21 & 0.84 & & 11 \\
\hline \multirow[t]{3}{*}{7} & $\mathrm{SGA} \sim$ male morph & intercept (helper) & -0.061 & 0.126 & -0.49 & 0.63 & 0.02 & 4 \\
\hline & & vs brown breeder & -0.092 & 0.162 & -0.56 & 0.58 & & 6 \\
\hline & & vs red/black breeder & -0.054 & 0.162 & -0.33 & 0.75 & & 6 \\
\hline \multirow[t]{3}{*}{8} & SGSNA $\sim$ male morph & intercept (helper) & 2.157 & 0.426 & 5.07 & $<0.001$ & 0.63 & 4 \\
\hline & & vs brown breeder & -2.304 & 0.55 & -4.19 & 0.001 & & 6 \\
\hline & & vs red/black breeder & -2.277 & 0.55 & -4.14 & 0.001 & & 6 \\
\hline \multirow[t]{2}{*}{9} & SPTA $\sim$ male morph & intercept (brown breeder) & 0.001 & 0.001 & 1.63 & 0.20 & 0.42 & 2 \\
\hline & & vs red/black breeder & -0.001 & 0.001 & -1.46 & 0.24 & & 3 \\
\hline
\end{tabular}

* Pathway numbers correspond to those outlined in Figure 1.

$\S$ Coefficient estimates for paths 1-5 denote standardized effect size $r$ and those for paths $6-9$ are in the original units. Statistically significant (or marginally non-significant) effects are shown in bold text. TA=testis size asymmetry, SGA=seminal glomerus size asymmetry, SGSNA=seminal glomerus sperm number asymmetry, SPTA=proportion of sperm producing tissue asymmetry, BM=body mass, CTM=combined testes mass. 

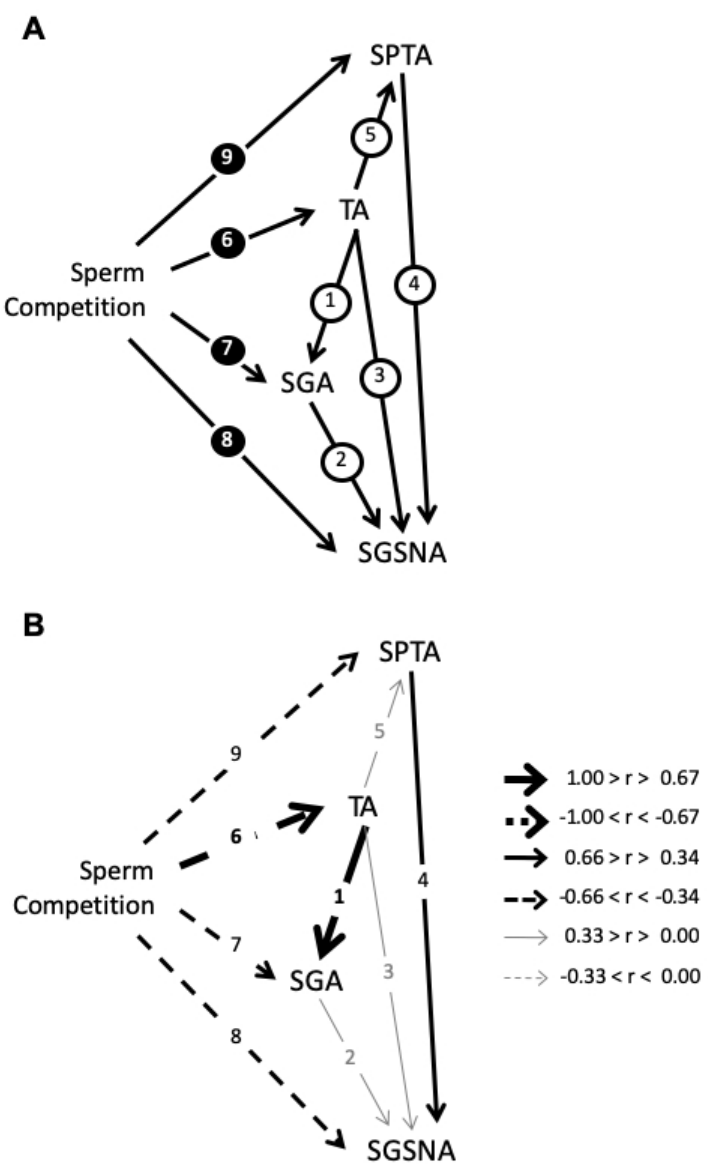

Schematic representation of the direct associations between side-correspondent development (paths 1-5) or sperm competition (paths 6-9) and four primary sexual trait asymmetries along the male reproductive tract: testis size asymmetry (TA), seminal glomerus size asymmetry (SGA), seminal glomerus sperm number asymmetry (SGSNA), and proportion of sperm producing tissue asymmetry (SPTA). Sperm competition was measured as relative testes size (combined testes mass, controlling for body mass). A: General schematic representation; B: Patterns observed at the interspecific level. Arrow thickness denotes standardized effect size $r$ and the style the direction of the association (solid and dashed for positive and negative, respectively). See Table 1 for complete statistical output.

$$
190 \times 275 \mathrm{~mm}(96 \times 96 \mathrm{DPI})
$$



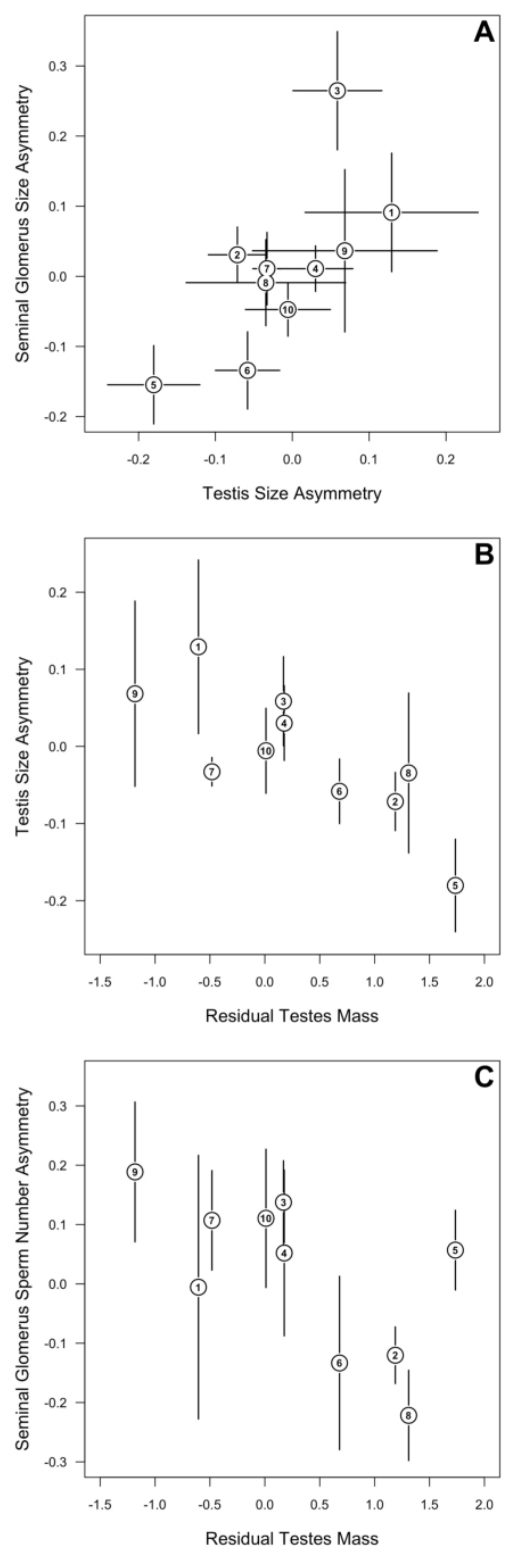

Scatterplots (mean \pm s.e.) representing the three statistically significant and/or strongest (standardized effect size $r>|0.66|$ ) interspecific associations (see Figure 1 ). (A) positive relationship between testis size asymmetry and seminal glomerus size asymmetry (path 1); (B) negative association between relative testes size and testis size asymmetry (path 6); and (C) negative association between relative testes size and seminal glomerus sperm number asymmetry (path 8). Here, unlike in the analysis, relative testes size is represented as the residuals of a phylogenetically controlled linear model of testes mass on body mass, using standardized variables. Asymmetry values are scale-free indices (see main text for details), with the absolute value reflecting the degree of difference and the sign denoting the directional bias (positive and negative for left- or right-bias, respectively). Species codes: $1=$ lovely fairy-wren $(n=4), 2=$ superb fairywren $(n=6), 3=$ red-winged fairy-wren $(n=6), 4=$ variegated fairy-wren $(n=5), 5=$ white-winged fairy-wren $(n=6), 6=$ red-backed fairy-wren $(n=20), 7=$ blue-breasted fairy-wren $(n=5), 8=$ splendid fairy-wren $(n=6)$, $9=$ southern emu-wren $(n=6), 10=$ striated grasswren $(n=6)$.

$941 \times 2288 \mathrm{~mm}(72 \times 72 \mathrm{DPI})$ 
55

56

57

58

59 


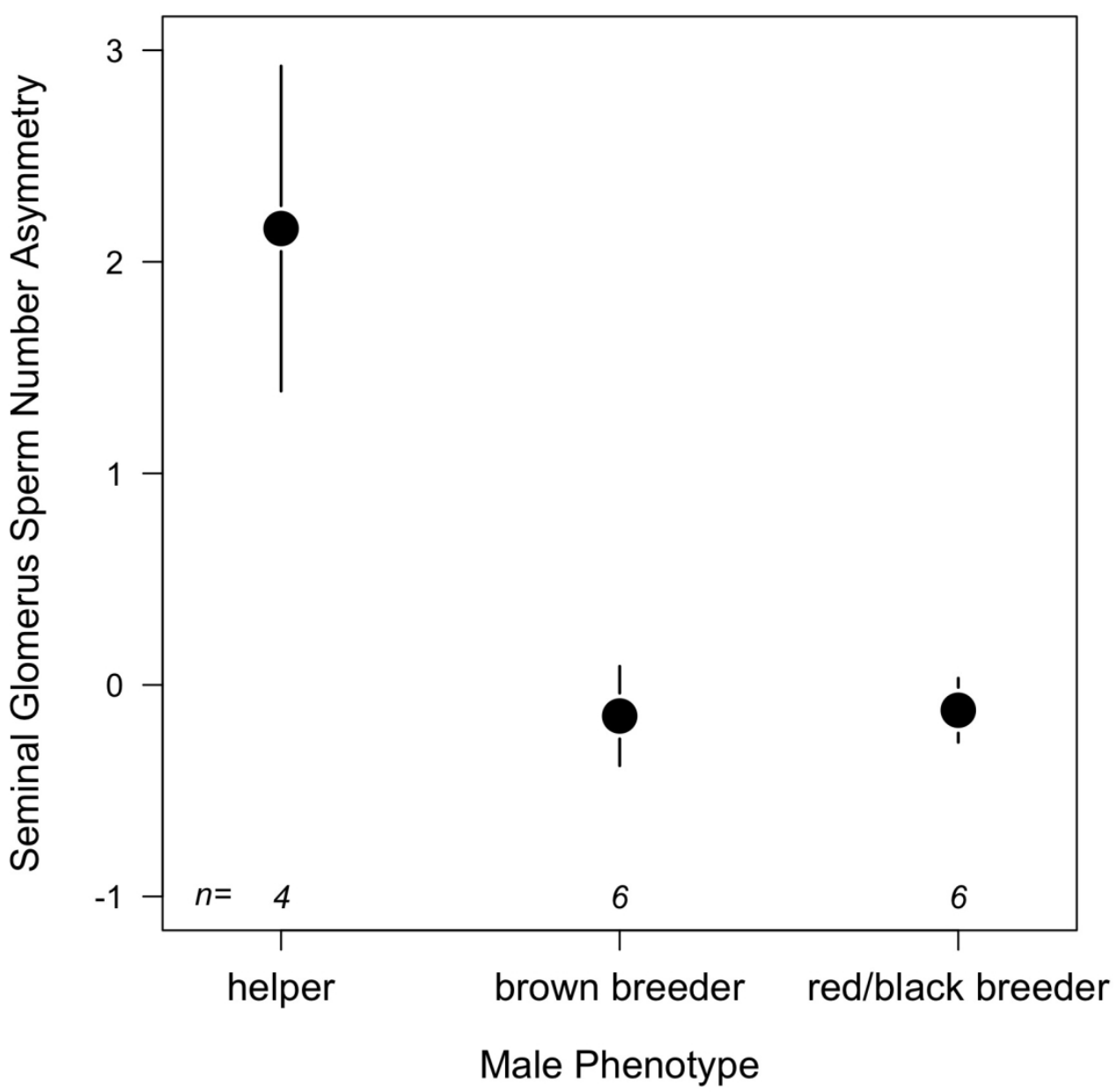

Differences in the asymmetry in the number of sperm in the seminal glomerus (mean \pm s.e.) between the three male morphs in the red-backed fairy-wren.

$624 \times 624 \mathrm{~mm}(72 \times 72 \mathrm{DPI})$ 


\section{Asymmetries in reproductive anatomy: insights from promiscuous songbirds}

Supplementary Table S1. Comparison of alternative paths to explain interspecific variation in asymmetry 2 along the reproductive tract in malurids. Repeat of the analyses presented in Table1 using species-specific testis asymmetry indices calculated from species-specific left and right testis mean mass and length values.

\begin{tabular}{|c|c|c|c|c|c|c|c|c|c|}
\hline pathway* & model & coefficient $\S$ & estimate & s.e. & $\mathrm{t}$ & $\mathrm{p}$ & ML lambda & $\mathrm{R}^{2}$ & $\mathrm{n}$ \\
\hline \multicolumn{10}{|c|}{ Side-correspondent development } \\
\hline \multirow[t]{2}{*}{1} & SGA $\sim$ TA & intercept & -0.014 & 0.237 & -0.06 & 0.954 & 0.00 & 0.491 & 10 \\
\hline & & TAsize & 0.690 & 0.248 & 2.777 & 0.024 & & & \\
\hline \multirow[t]{2}{*}{2} & SGSNA SGA & intercept & 0.612 & 1.141 & 0.536 & 0.606 & 1.00 & 0.327 & 10 \\
\hline & & SGA & 0.453 & 0.230 & 1.971 & 0.084 & & & \\
\hline \multirow[t]{2}{*}{3} & SGSNA $\sim$ TA & intercept & 0.024 & 0.272 & 0.089 & 0.931 & 0.00 & 0.353 & 10 \\
\hline & & TAsize & 0.595 & 0.285 & 2.09 & 0.070 & & & \\
\hline \multirow[t]{2}{*}{4} & SGSNA SPTA & intercept & 0.451 & 1.217 & 0.37 & 0.724 & 1.00 & 0.154 & 8 \\
\hline & & tissueA & 0.307 & 0.294 & 1.044 & 0.337 & & & \\
\hline \multirow[t]{2}{*}{5} & SPTA $\sim$ TA & intercept & 0.072 & 0.387 & 0.187 & 0.858 & 0.00 & 0.051 & 8 \\
\hline & & TAsize & 0.247 & 0.433 & 0.57 & 0.589 & & & \\
\hline \multicolumn{10}{|c|}{ Sperm competition (relative testes mass) } \\
\hline \multirow[t]{3}{*}{6} & $\mathbf{T A} \sim \mathbf{B M}+\mathbf{C T M}$ & intercept & -0.01 & 0.199 & -0.048 & 0.963 & 0.00 & 0.697 & 10 \\
\hline & & $\mathrm{BM}$ & 0.368 & 0.223 & 1.649 & 0.143 & & & \\
\hline & & CTM & -0.898 & 0.224 & -4.016 & 0.005 & & & \\
\hline \multirow[t]{3}{*}{7} & $\mathrm{SGA} \sim \mathrm{BM}+\mathrm{CTM}$ & intercept & -0.019 & 0.328 & -0.058 & 0.956 & 0.00 & 0.153 & 10 \\
\hline & & $\mathrm{BM}$ & 0.216 & 0.368 & 0.587 & 0.576 & & & \\
\hline & & CTM & -0.409 & 0.368 & -1.11 & 0.304 & & & \\
\hline \multirow[t]{3}{*}{8} & SGSNA $\sim$ BM + CTM & intercept & 0.015 & 0.258 & 0.059 & 0.955 & 0.00 & 0.493 & 10 \\
\hline & & $\mathrm{BM}$ & 0.487 & 0.289 & 1.685 & 0.136 & & & \\
\hline & & СТM & -0.721 & 0.29 & -2.49 & 0.042 & & & \\
\hline \multirow[t]{3}{*}{9} & $\mathrm{SPTA} \sim \mathrm{BM}+\mathrm{CTM}$ & intercept & 0.06 & 0.35 & 0.173 & 0.87 & 0.00 & 0.296 & 8 \\
\hline & & $\mathrm{BM}$ & 0.288 & 0.351 & 0.822 & 0.448 & & & \\
\hline & & CTM & -0.53 & 0.374 & -1.418 & 0.215 & & & \\
\hline
\end{tabular}

* Pathway numbers correspond to those outlined in Figure 1.

$\S$ Coefficient estimates denote standardized effect size $r$, with statistically significant (or marginally non-significant) effects shown in bold text. TA=testis size asymmetry, $\mathrm{SGA}=$ seminal glomerus size asymmetry, $\mathrm{SGSNA}=$ seminal glomerus sperm number asymmetry, $\mathrm{SPTA}=$ proportion of sperm producing tissue asymmetry, $\mathrm{BM}=$ body mass, $\mathrm{CTM}=$ combined testes mass, $\mathrm{ML}$ lambda=maximum likelihood estimated lambda. 


\section{Asymmetries in reproductive anatomy: insights from promiscuous songbirds}

Supplementary Table S2. Asymmetries in primary reproductive traits (mean, range and sample size) across 10 species of Maluridae. Asymmetry values are scale-

free (see main text for details), with the absolute value reflecting the degree of difference and the sign denoting the directional bias (positive and negative for left- or right-bias, respectively). Note that red-backed fairy-wren data exclude helpers but include both red/black and brown male breeder morphs. Species-means asymmetry indices were calculated by averaging across individual asymmetry indices (cf. asymmetry indices calculated from species-means side-specific trait values as done in Calhim and Montgomerie 2015).

\begin{tabular}{|c|c|c|c|c|c|c|c|c|c|c|c|c|c|c|c|c|c|c|c|c|c|c|}
\hline \multirow[t]{2}{*}{ Species } & \multicolumn{4}{|c|}{$\begin{array}{l}\text { Testis size asymmetry } \\
\text { (TA) }\end{array}$} & \multicolumn{4}{|c|}{$\begin{array}{l}\text { Seminal glomerus size } \\
\text { asymmetry (SGA) }\end{array}$} & \multicolumn{4}{|c|}{$\begin{array}{l}\text { Seminal glomerus sperm number } \\
\text { asymmetry (SGSNA) }\end{array}$} & \multicolumn{4}{|c|}{$\begin{array}{l}\text { Proportion of sperm producing tissue } \\
\text { asymmetry (SPTA) }\end{array}$} & \multicolumn{4}{|c|}{ Testis shape asymmetry } & \multicolumn{2}{|c|}{$\begin{array}{l}\text { Gizzard } \\
\text { volume }\left(\mathrm{cm}^{2}\right)\end{array}$} \\
\hline & mean & $\min$ & $\max$ & $\mathrm{n}$ & mean & $\min$ & $\max$ & $\mathrm{n}$ & mean & $\min$ & $\max$ & $\mathrm{n}$ & mean & $\min$ & $\max$ & $\mathrm{n}$ & mean & $\min$ & $\max$ & $\mathrm{n}$ & mean & $\mathrm{n}$ \\
\hline $\begin{array}{l}\text { Striated grasswren } \\
\text { (Amytornis striatus) }\end{array}$ & -0.01 & -0.18 & 0.23 & 6 & -0.05 & -0.20 & 0.13 & 5 & 0.11 & -0.28 & 0.79 & 6 & 0.0011 & -0.0039 & 0.004 & 3 & 0.20 & 0.07 & 0.34 & 6 & 0.809 & 2 \\
\hline $\begin{array}{l}\text { Lovely fairy-wren } \\
\text { (Malurus amabilis) }\end{array}$ & 0.13 & -0.09 & 0.66 & 4 & 0.09 & -0.22 & 0.41 & 4 & -0.01 & -0.50 & 1.02 & 4 & - & - & - & - & 0.13 & -0.04 & 0.29 & 4 & - & - \\
\hline $\begin{array}{l}\text { Superb fairy-wren } \\
\text { (Malurus cyaneus) }\end{array}$ & -0.07 & -0.23 & 0.07 & 6 & 0.03 & -0.13 & 0.17 & 6 & -0.12 & -0.29 & 0.07 & 6 & -0.0013 & -0.0024 & 0.000 & 6 & -0.05 & -0.12 & 0.05 & 5 & 0.353 & 3 \\
\hline $\begin{array}{l}\text { Red-winged fairy-wren } \\
\text { (Malurus elegans) }\end{array}$ & 0.06 & -0.18 & 0.34 & 6 & 0.26 & 0.05 & 0.79 & 6 & 0.14 & -0.20 & 0.42 & 6 & - & - & - & - & 0.06 & -0.11 & 0.35 & 5 & - & - \\
\hline $\begin{array}{l}\text { Variegated fairy-wren } \\
\text { (Malurus lamberti) }\end{array}$ & 0.03 & -0.13 & 0.24 & 5 & 0.01 & -0.13 & 0.12 & 4 & 0.05 & -0.33 & 0.82 & 5 & 0.0009 & -0.0025 & 0.004 & 5 & -0.14 & -0.56 & 0.19 & 5 & 0.145 & 1 \\
\hline $\begin{array}{l}\text { White-winged fairy-wren } \\
\text { (Malurus leucopterus) }\end{array}$ & -0.18 & -0.47 & 0.04 & 6 & -0.15 & -0.38 & 0.07 & 6 & 0.06 & -0.19 & 0.38 & 6 & -0.0003 & -0.0015 & 0.001 & 4 & 0.05 & -0.11 & 0.22 & 6 & 0.330 & 2 \\
\hline $\begin{array}{l}\text { Red-backed fairy-wren } \\
\text { (Malurus melanocephalus) }\end{array}$ & -0.06 & -0.25 & 0.32 & 20 & -0.13 & -0.37 & 0.11 & 12 & -0.13 & -0.69 & 0.89 & 12 & 0.0004 & -0.0011 & 0.002 & 5 & 0.05 & -0.20 & 0.38 & 20 & - & - \\
\hline $\begin{array}{l}\text { Blue-breasted fairy-wren } \\
\text { (Malurus pulcherrimus) }\end{array}$ & -0.03 & -0.13 & 0.03 & 5 & 0.01 & -0.24 & 0.20 & 5 & 0.11 & -0.16 & 0.42 & 5 & 0.0042 & -0.0024 & 0.012 & 5 & -0.02 & -0.10 & 0.12 & 5 & 0.339 & 1 \\
\hline $\begin{array}{l}\text { Splendid fairy-wren } \\
\text { (Malurus splendens) }\end{array}$ & -0.03 & -0.35 & 0.46 & 6 & -0.01 & -0.18 & 0.36 & 6 & -0.22 & -0.67 & 0.01 & 6 & -0.0008 & -0.0044 & 0.005 & 6 & 0.06 & -0.09 & 0.38 & 6 & - & - \\
\hline $\begin{array}{l}\text { Southern emu-wren } \\
\text { (Stipiturus malachurus) }\end{array}$ & 0.07 & -0.56 & 0.47 & 6 & 0.04 & -0.41 & 0.41 & 5 & 0.19 & -0.45 & 0.51 & 5 & 0.0005 & -0.0118 & 0.013 & 6 & 0.05 & -0.10 & 0.21 & 6 & - & - \\
\hline
\end{tabular}




\section{Asymmetries in reproductive anatomy: insights from promiscuous songbirds}

Supplementary Table S3. Asymmetries in primary reproductive traits (mean, range and sample size) across male morph in red-backed fairy-wrens. Asymmetry

values are scale-free (see main text for details), with the absolute value reflecting the degree of difference and the sign denoting the directional bias (positive and negative for left- or right-bias, respectively).

\begin{tabular}{|c|c|c|c|c|c|c|c|c|c|c|c|c|c|c|c|c|}
\hline \multirow[t]{2}{*}{ Phenotype } & \multicolumn{4}{|c|}{ Testis size asymmetry (TA) } & \multicolumn{4}{|c|}{$\begin{array}{l}\text { Seminal glomerus size } \\
\text { asymmetry (SGA) }\end{array}$} & \multicolumn{4}{|c|}{$\begin{array}{l}\text { Seminal glomerus sperm number } \\
\text { asymmetry (SGSNA) }\end{array}$} & \multicolumn{4}{|c|}{$\begin{array}{l}\text { Proportion of sperm producing tissue } \\
\text { asymmetry (SPTA) }\end{array}$} \\
\hline & mean & $\min$ & $\max$ & $\mathrm{n}$ & mean & $\min$ & $\max$ & $\mathrm{n}$ & mean & $\min$ & $\max$ & $\mathrm{n}$ & mean & $\min$ & $\max$ & $\mathrm{n}$ \\
\hline Red/black breeder & -0.03 & -0.25 & 0.32 & 11 & -0.12 & -0.37 & 0.11 & 6 & -0.12 & -0.68 & 0.39 & 6 & -0.0002 & -0.0011 & 0.0009 & 3 \\
\hline Brown breeder & -0.09 & -0.20 & 0.02 & 9 & -0.15 & -0.27 & 0.00 & 6 & -0.15 & -0.69 & 0.89 & 6 & 0.0013 & 0.0004 & 0.0022 & 2 \\
\hline Helper & -0.02 & -0.10 & 0.11 & 4 & -0.06 & -0.51 & 0.46 & 4 & 2.16 & 0.03 & 3.45 & 4 & - & - & - & - \\
\hline
\end{tabular}




\section{Asymmetries in reproductive anatomy: insights from promiscuous songbirds}

16 Supplementary Table S4. Effect of time of sampling on the asymmetry of sperm numbers stored in the seminal glomerus across species. Results obtained using a PGLS analyses using standardized variables and a

18 phylogeny where the different individuals are coded as polytomies at their corresponding species node ( $\mathrm{n}=50$ individuals of $n=9$ species).

\begin{tabular}{lllllllll} 
model & coefficient $\S$ & estimate & s.e. & $\mathrm{t}$ & $\mathrm{p}$ & ML lambda & $\mathrm{R}^{2}$ & $\mathrm{n}$ \\
\hline SGSNA $\sim$ sampling time & intercept & -0.035 & 0.138 & -0.255 & 0.800 & 0.00 & $<0.001$ & 50 \\
& time & 0.040 & 0.155 & 0.258 & 0.798 & & & \\
\hline
\end{tabular}

24 Supplementary Table S5. Effect of time of sampling on the asymmetry of sperm numbers stored in the seminal glomerus within red-backed fairy-wrens. Since the variable time had a bimodal distribution, we 26 transformed it into a two-level factor ('early' $=6: 00-10: 00$ and 'late' $=16: 00-19: 00$, ). We test for an interaction between sampling time and morph using a 2-way ANOVA with Type III sum of squares. The 'Anova' function in 28 the R package 'car' was used for the latter.

\begin{tabular}{llllll} 
& coefficient $\S$ & Sum of Squares & d.f. & F & p \\
\hline Two-way ANOVA & (intercept) & 2.47 & 1 & 8.09 & 0.019 \\
(Type III SS) & Morph & 4.15 & 2 & 6.78 & $\mathbf{0 . 0 1 6}$ \\
& Time & 3.42 & 1 & 11.16 & $\mathbf{0 . 0 0 9}$ \\
& Morph*Time & 3.13 & 2 & 5.12 & $\mathbf{0 . 0 3 3}$ \\
& Residual & 2.75 & 9 & & \\
\hline
\end{tabular}




\section{Asymmetries in reproductive anatomy: insights from promiscuous songbirds}

32 Supplementary Figure S1. Relationship between testis asymmetry in (A) size and (B) shape (mean \pm s.e.) and gizzard volume (as a ratio to body mass) in five Maluridae species. Species codes follow those in Figure

$342: 2=$ superb fairy-wren, $4=$ =variegated fairy-wren, $5=$ =white-winged fairy-wren, $7=$ =blue-breasted fairy-wren, $10=$ striated grasswren.
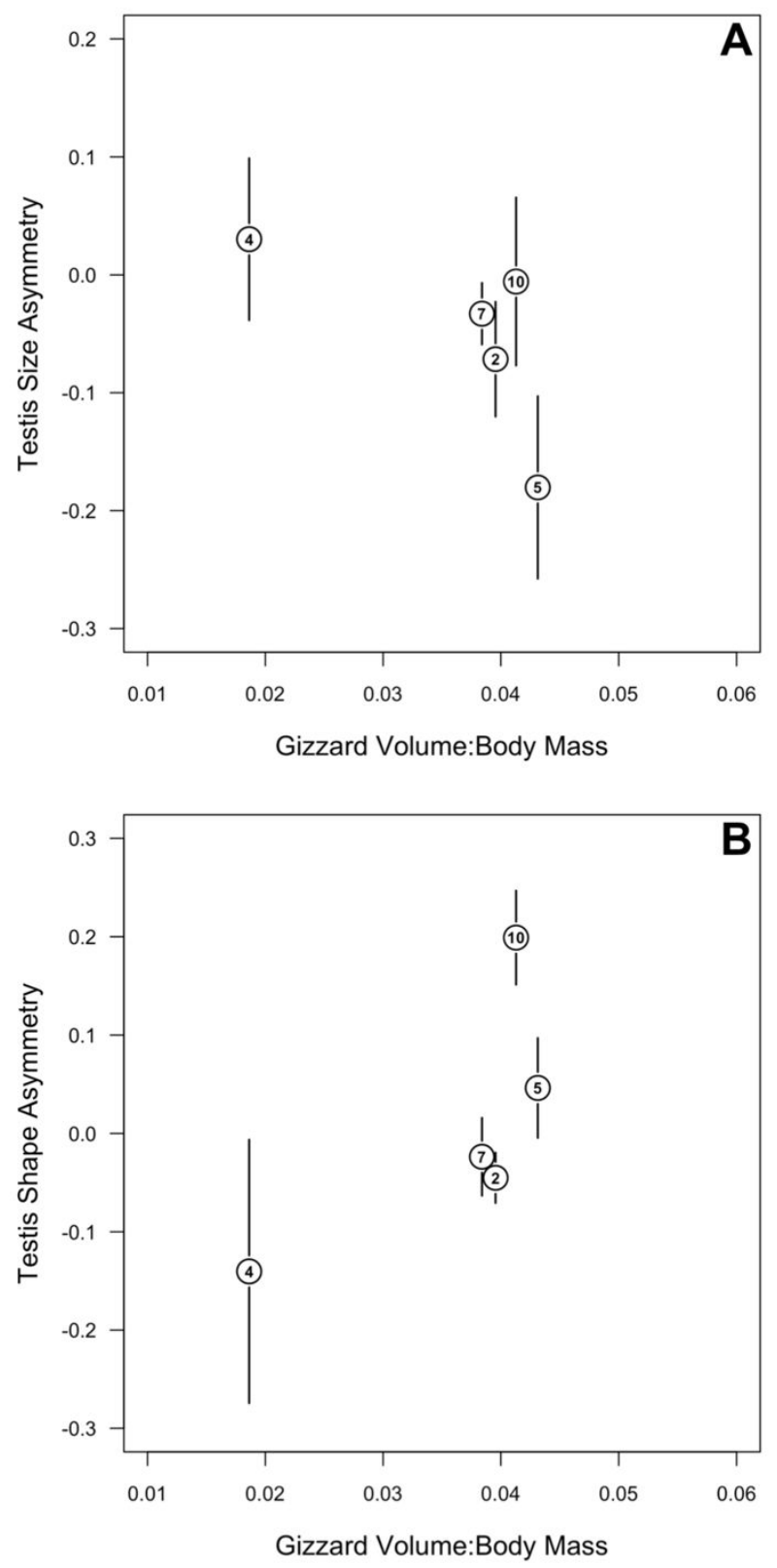


\section{Asymmetries in reproductive anatomy: insights from promiscuous songbirds}

38 Supplementary Figure S2. Relationship between time of sampling and asymmetry in the number of sperm stored in the seminal glomera (SGSNA). (A) Interspecific patterns (breeders only) and (B) Intraspecific

40 patterns in red-backed fairy-wrens.
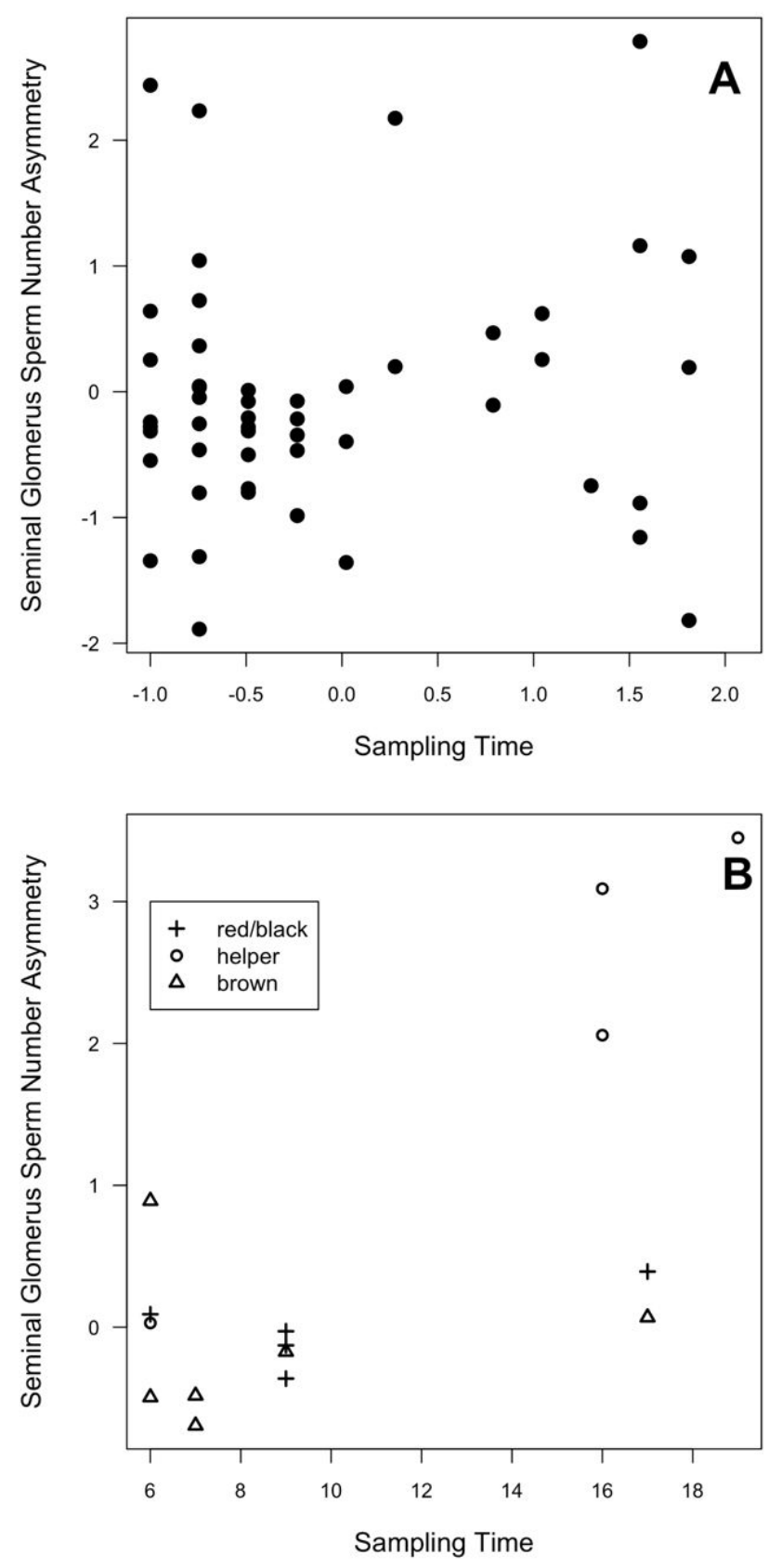

42

Page 6 of 6 